\title{
Factors involved in patient choice of oral or vaginal treatment for vulvovaginal candidiasis
}

This article was published in the following Dove Press journal:

Patient Preference and Adherence

13 December 2013

Number of times this article has been viewed

\section{Jack D Sobel}

Division of Infectious Diseases, Wayne State University School of Medicine, Detroit, MI, USA
Correspondence: Jack D Sobel Division of Infectious Diseases, Harper University Hospital, 3990 John R,

Detroit, MI 4820I, USA

Tel + I 3137457105

Fax + I 3139930302

Email jsobel@med.wayne.edu
Abstract: Vulvovaginal candidiasis (VVC) is an extremely common cause of vaginal symptoms in women. Multiple antifungal products are available by either the oral or vaginal route, although no new drugs have become available for two decades. Given the therapeutic equivalence of the antimycotic agents and their routes of administration, the specific drug and formulation selected is entirely arbitrary in relation to final treatment outcome. Nevertheless, multiple factors affecting preference, both practitioner-dependent and patient-dependent, impact on selection of a specific drug and route of administration.

Keywords: antifungal drugs, antimycotics, Candida vaginitis, vulvovaginal candidiasis

\section{Introduction}

In some instances, a woman's opportunity to be involved in the choice of the oral or vaginal route for antifungal therapy is nonexistent when treating vulvovaginal candidiasis (VVC). However, in many Western countries, topical antifungal therapy has become available over the counter (OTC), in which case the patient has total control in self-diagnosis and obtaining topical antimycotic therapy. Certainly in North America, most women seek and obtain therapy by the OTC route. ${ }^{1}$ However, in Western countries, most oral or systemic antifungal agents are still only available by prescription and there is little opportunity for women to express a personal preference in determining the route of administration for prescription drugs. In a few countries, stat doses of oral azoles have now become available OTC.

Regardless of route, choosing among the multiple brands is usually dictated by financial considerations, and topical OTC agents are now available as branded, generic, or local pharmacy-compounded. The many advantages and disadvantages of the OTC availability of vaginal antimycotic agents are outside the scope of this review.

Back in the practitioner's office, most clinicians routinely exercise and impose their personal preferences when prescribing antimycotics, assuming equivalence of efficacy for the different routes of therapy. Cost considerations incurred by insurance companies frequently dominate and dictate treatment choice. As such, cost awareness is a perfectly reasonable, if not essential, consideration on the part of providers and patients. However, cost should not be the only factor. In many societies, practitioners traditionally impose their preferences without debate or discourse, and patient participation is neither invited nor tolerated. The purpose of this manuscript is to review considerations regarding patient choice of oral or vaginal treatment for VVC. 


\section{Prioritizing patient preferences}

Although not the purpose of this review, the most important consideration that patients should have at the time of treatment designation is not the nature of therapy but whether the diagnosis of VVC has been confirmed. Unfortunately, clinicians still practice in the absence of a rapid, reliable, inexpensive point-of-care diagnostic test for VVC. Accordingly, practitioners widely and frequently adopt an empiric approach in which antimycotic therapy is prescribed for symptomatic women without VVC. Poor diagnostic skills are unfortunately the modern norm. It is worth emphasizing that self-diagnosis by women is equally unreliable. Another consideration is the possibility of a mixed vaginal infection involving more than one vaginal pathogen contributing to the patient's signs and symptoms. ${ }^{2}$

\section{Treatment options available Topical}

An array of topical vaginal antifungal agents is available (Table 1). With the exception of nystatin, a polyene product, all the antimycotics belong to the azole drug class. All the imidazoles are available OTC as creams or suppositories (ovules) at different concentrations which, in turn, determines the duration of self-administered therapy. Multiple in vitro and clinical studies indicate that the imidazoles are of equal potency in inhibiting and killing yeast pathogens. ${ }^{3-9}$ The products available are identical in terms of achieving short-term

Table I Treatment options for acute vulvovaginal candidiasis

\begin{tabular}{|c|c|c|}
\hline Drug & Formulation & Dose \\
\hline Nystatin & $100,000 \mathrm{U}$ vaginal tablet & $100,000 \mathrm{U} / \mathrm{I} 4$ days \\
\hline \multirow[t]{2}{*}{ Butoconazole } & $2 \%$ sustained release cream & 5 g/l day \\
\hline & $2 \%$ cream & $5 \mathrm{~g} / 7$ days \\
\hline \multirow[t]{5}{*}{ Clotrimazole } & $1 \%$ cream & $5 \mathrm{~g} / 7$ days \\
\hline & $2 \%$ cream & $5 \mathrm{~g} / 3$ days \\
\hline & $100 \mathrm{mg}$ vaginal suppository & $100 \mathrm{mg} / 7$ days \\
\hline & $200 \mathrm{mg}$ vaginal suppository & $200 \mathrm{mg} / 3$ days \\
\hline & $500 \mathrm{mg}$ vaginal suppository & $500 \mathrm{mg} / \mathrm{I}$ day \\
\hline \multirow[t]{4}{*}{ Miconazole } & $2 \%$ cream & $5 \mathrm{~g} / 7$ days \\
\hline & $100 \mathrm{mg}$ vaginal suppository & $100 \mathrm{mg} / 7$ days \\
\hline & $200 \mathrm{mg}$ vaginal suppository & $200 \mathrm{mg} / 3$ days \\
\hline & I,200 mg vaginal suppository & $\mathrm{I}, 200 \mathrm{mg} / \mathrm{I}$ day \\
\hline \multirow[t]{3}{*}{ Terconazole } & $0.4 \%$ cream & $5 \mathrm{~g} / 7$ days \\
\hline & $0.8 \%$ cream & $5 \mathrm{~g} / 3$ days \\
\hline & $80 \mathrm{mg}$ vaginal suppository & $80 \mathrm{mg} / 3$ days \\
\hline \multirow[t]{2}{*}{ Tioconazole } & $2 \%$ cream & $5 \mathrm{~g} / 3$ days \\
\hline & $6.5 \%$ cream & 5 g/l day \\
\hline \multicolumn{3}{|l|}{ Oral } \\
\hline Fluconazole & & I50 mg single dose \\
\hline Itraconzole & & $200 \mathrm{mg}$ bid $\times 3$ days \\
\hline Ketoconazole & & $400 \mathrm{mg}$ bid $\times 3$ days \\
\hline
\end{tabular}

Abbreviation: bid, twice a day. and long-term cure, defined as rapid relief of symptoms and signs but not eradication of vaginal yeast. However, the individual topical imidazole products are not identical in terms of local side effects, ie, burning and irritation. In general, clotrimazole and its vehicle have the best reported tolerance. In contrast, tioconazole, butoconazole, and miconazole tend to be associated with more local adverse effects, as does terconazole, a topical triazole. However, for the most part, the topical azoles are well tolerated and equally effective. ${ }^{3-9}$ Use of a cream or suppository is arbitrary, and should be left to the patient to decide. Vulvar involvement in addition to vaginal symptoms mandates use of a cream product to be applied to the inflamed skin. In addition, where vulvar disease is more severe, many practitioners add a topical steroid for local application to the vulva as a separate single formulation or combined with an antifungal cream or ointment. Intravaginal application of a steroid is not necessary. Duration of therapy and hence drug concentration should be dictated by the severity of vulvovaginitis. ${ }^{10}$ Mild clinical manifestations usually respond to a single dose or short duration of treatment, ie, 1-3 days, whereas more severe signs and symptoms need topical therapy for 5-7 days.

Topical triazoles such as terconazole are available by prescription only but offer no advantage in the treatment of vulvovaginitis. Several azole products are claimed by their manufacturers to have an enhanced spectrum of activity against a broader range of Candida species, but this has not been validated in clinical studies. ${ }^{11}$

\section{Oral}

Three oral antimycotics have been used widely in the treatment of VVC, ie, fluconazole, itraconazole, and ketoconazole. It is remarkable that no new antimycotics, including oral agents, have been developed in the last two decades. In addition, hepatotoxicity has resulted in withdrawal of ketoconazole from many formularies worldwide. This is perhaps regrettable, given that the efficacy of ketoconazole is not questioned and it may serve as the only effective oral agent for some azole-resistant Candida species.

Accordingly, fluconazole remains the dominant oral triazole used worldwide and is now generic in most countries, resulting in increased affordability. Generic antimycotics are generally of equivalent potency and quality. An important fact to be emphasized in this review is that oral and topical antifungal agents are equally effective in treating VVC. ${ }^{6,11-13}$ Oral fluconazole as a single agent is remarkably efficacious for VVC of mild or moderate severity, but additional doses may be required for more severe VVC; this agent 
is never prescribed daily because of its pharmacokinetic characteristics, but every 72 hours for two or three doses at a maximum. ${ }^{10,14}$ Essentially, there are no specific indications for use of oral azoles, and their use is driven by public demand for convenience. The only exception is their advantage in the minority of women who do not tolerate topical azoles. In contrast, although extremely safe and well tolerated, oral azoles do expose women to the infrequent risk of gastrointestinal and systemic side effects.

\section{The eternal debate}

Given their clinical equivalence in terms of efficacy, debate has continued for two decades over the advantages of topical versus oral antimycotics for VVC, bearing in mind the ready OTC access of women worldwide to topical antimycotics of high efficacy. If a woman fails a course of topical antimycotics, it is usually, but not invariably, because she did not have VVC in the first place. Failure of an OTC product is unlikely to be reversed by a second oral or topical antifungal agent, generally prescribed by a practitioner and often without seeing the patient. A topical agent may fail for proven VVC because of a local reaction to the vehicle used in the cream or suppository, causing local burning and pain and replacing the original symptoms of discharge and itch. Another reason is lack of compliance due to "real life" inconvenience.

Accordingly, patient preference for therapy operates only in the practitioner's office and after the diagnosis is confirmed. Women at this juncture have the opportunity to intervene and influence the practitioner's choice of which antimycotic agent to prescribe, bearing in mind that therapeutic equivalence is the dominant overriding consideration and is not an issue. As mentioned above, with extensive vulvitis, a topical steroid and hence a topical antimycotic or a combination of oral azole plus a topical steroid is advisable.

What about speed of action? Topical agents do result in initial relief of symptoms a few hours earlier than oral agents. In spite of the putative advantage of speed of action and freedom from systemic toxicity, women for two decades have overwhelmingly preferred the convenience of oral azole antifungal therapy over messy topical creams and suppositories that often need to be applied daily for 7 days. This conclusion has been supported by multiple studies. ${ }^{11}$

Fluconazole has now been in popular use for two decades, dominating the treatment choice for VVC during this time. Safety has been a major advantage of fluconazole use, with gastrointestinal intolerance and rashes being uncommon. Largely unknown is the problem of hair loss with longterm use. Other rare complications include hepatotoxicity and Stevens-Johnson syndrome. Even when inadvertently prescribed for pregnant women, a recent large cohort study in Denmark has added to the multiple previous studies confirming its safety. ${ }^{15,16}$ Nevertheless, none of the oral agents have been approved for use during pregnancy and this recommendation is supported by most experts.

It is of interest that choice of route of administration is not infrequently simply a function of personal and cultural influences. A summary of the various considerations influencing the preferred route is shown in Table 2. When women with recurrent $\mathrm{VVC}$ are required to receive long-term maintenance antifungal therapy, clearly the convenience of weekly oral therapy over 6 months weighs heavily in selecting weekly oral vaginal therapy. ${ }^{17,18}$

Table 2 Considerations in selecting azole treatment for VVC

\begin{tabular}{|c|c|c|c|}
\hline & Topical & Oral & Comment \\
\hline Pregnant & Recommended & Not recommended & Nystatin per vagina preferred by some \\
\hline Speed of action & Slightly quicker & Slight delay & Minimal difference unless extensive vulvitis \\
\hline Efficacy & Excellent & Excellent & $\begin{array}{l}\text { No difference but for both duration } \\
\text { depends on severity }\end{array}$ \\
\hline OTC availability & Widely available & No & $\begin{array}{l}\text { Oral therapy available without prescription } \\
\text { in few countries }\end{array}$ \\
\hline Convenience & $\begin{array}{l}\text { Depends upon duration } \\
\text { Less }\end{array}$ & Major advantage & Validated \\
\hline Women's preference in studies & Rare & Overwhelming & Multiple studies validate \\
\hline Local side effects & Infrequent & - & \\
\hline Systemic adverse effects & - & Infrequent & \\
\hline Cost & \multicolumn{3}{|c|}{ Depends upon country and insurance } \\
\hline Selection of non-albicans Candida & Unknown & Speculated possible & Inconclusive data \\
\hline Contribution to azole resistance & Unknown & With long-term use & Inconclusive data \\
\hline Recurrent VVC (maintenance) & Inconvenient & Convenient & Convenience and proven efficacy \\
\hline
\end{tabular}

Abbreviations: OTC, over-the-counter; VVC, vulvovaginal candidiasis. 


\section{Conclusion}

Given the therapeutic efficacy and equivalence of the individual antifungal agents as well as route of administration, treatment selection should be driven by the patient's personal preference. Clinicians should defer to the patient's wishes after discussing the very minor advantages and disadvantages of each route of antifungal drug administration based upon individual patient characteristics. Often cultural and insurance/cost-based considerations ultimately determine drug selection and route of administration.

\section{Disclosure}

The author reports no conflict of interest in this work.

\section{References}

1. Ferris DG, Nyirjesy P, Sobel JD, Soper D, Pavletic A, Litaker MS. Overthe-counter antifungal drug misuse associated with patient-diagnosed vulvovaginal candidiasis. Obstet Gynecol. 2002;99:419-425.

2. Sobel JD, Subramanian C, Foxman B, Fairfax M, Gygax SE. Mixed vaginitis - more than coinfection and with therapeutic implications. Curr Infect Dis Rep. 2013;15:104-108.

3. Mendling W, Brasch J. German Society for Gynecology and Obstetrics, Guideline vulvovaginal candidosis (2010) of the German Society for Gynecology and Obstetrics, the Working Group for Infections and Infect immunology in Gynecology and Obstetrics, the German Society of Dermatology, the Board of German Dermatologists and the German Speaking Mycological Society. Mycoses. 2012;55 Suppl 3:1-13.

4. [No authors listed]. National guideline for the management of vulvovaginal candidiasis. Clinical Effectiveness Group (Association of Genitourinary Medicine and the Medical Society for the Study of Venereal Diseases). Sex Transm Infect. 1999;75 Suppl 1:S19-S20.

5. Pappas PG, Kauffman CA, Andes D, et al. Clinical practice guidelines for the management of candidiasis: 2009 update by the Infectious Diseases Society of America. Clin Infect Dis. 2009;48:503-535.

6. Reef SE, Levine WC, McNeil MM, et al. Treatment options for vulvovaginal candidiasis, 1993. Clin Infect Dis. 1995;20 Suppl 1: S80-S90.
7. British Association for Sexual Health and HIV. United Kingdom National Guideline on the Management of Vulvovaginal Candidiasis (2007). Available from: http://www.bashh.org/documents/1798.pdf. Accessed December 4, 2008.

8. Workowski KA, Berman S; Centers for Disease Control and Prevention. Sexually transmitted diseases treatment guidelines, 2010. MMWR Recomm Rep. 2010;59:1-110.

9. Young GL, Jewell D. Topical treatment for vaginal candidiasis (thrush) in pregnancy. Cochrane Database Syst Rev. 2001;4:CD000225.

10. Sobel JD, Kapernick PS, Zervos M, et al. Treatment of complicated Candida vaginitis: comparison of single and sequential doses of fluconazole. Am J Obstet Gynecol. 2001;185:363-369.

11. Watson MC, Grimshaw JM, Bond CM, Mollison J, Ludbrook A. Oral versus intra-vaginal imidazole and triazole anti-fungal treatment of uncomplicated vulvovaginal candidiasis (thrush). Cochrane Database Syst Rev. 2001;4:CD002845.

12. Sobel JD, Brooker D, Stein GE, et al. Single oral dose fluconazole compared with conventional clotrimazole topical therapy of Candida vaginitis. Fluconazole Vaginitis Study Group. Am J Obstet Gynecol. $1995 ; 172: 1263-1268$

13. Sobel JD, Faro S, Force RW, et al. Vulvovaginal candidiasis: epidemiologic, diagnostic, and therapeutic considerations. Am J Obstet Gynecol. 1998;178:203-211.

14. Houang ET, Chappatte O, Byrne D, Macrae PV, Thorpe JE. Fluconazole levels in plasma and vaginal secretions of patients after a 150-milligram single oral dose and rate of eradication of infection in vaginal candidiasis. Antimicrob Agents Chemother. 1990;34:909-910.

15. Mølgaard-Nielsen D, Pasternak B, Hviid A. Use of oral fluconazole during pregnancy and the risk of birth defects. N Engl J Med. 2013;369: 830-839.

16. Nørgaard M, Pedersen L, Gislum M, et al. Maternal use of fluconazole and risk of congenital malformations: a Danish population-based cohort study. J Antimicrob Chemother. 2008;62:172-176.

17. Sobel JD, Wiesenfeld HC, Martens M, et al. Maintenance fluconazole therapy for recurrent vulvovaginal candidiasis. NEngl J Med. 2004;351: 876-883.

18. Donders G, Bellen G, Byttebier G, et al. Individualized decreasing-dose maintenance fluconazole regimen for recurrent vulvovaginal candidiasis (ReCiDiF trial). Am J Obstet Gynecol. 2008;199:613. e1-e9.
Patient Preference and Adherence

\section{Publish your work in this journal}

Patient Preference and Adherence is an international, peer-reviewed, open access journal focusing on the growing importance of patient preference and adherence throughout the therapeutic continuum. Patient satisfaction, acceptability, quality of life, compliance, persistence and their role in developing new therapeutic modalities and compounds to

\section{Dovepress}

optimize clinical outcomes for existing disease states are major areas of interest. This journal has been accepted for indexing on PubMed Central. The manuscript management system is completely online and includes a very quick and fair peer-review system. Visit http://www.dovepress.com/ testimonials.php to read real quotes from published authors. 